\title{
PERHITUNGAN PATHLOSS TEKNOLOGI LONG TERM EVOLUTION (LTE) BERDASARKAN PARAMETER JARAK E Node-B TERHADAP MOBILE STATION DI BALIKPAPAN
}

\author{
Maria Ulfah \\ Jurusan Teknik Elektronika, Politeknik Negeri Balikpapan \\ Corresponding author, e-mail : maria.ulfah@poltekba.ac.id
}

\begin{abstract}
Abstrak-Semakin jauh jarak antara pengirim dan penerima dalam komunikasi seluler akan mengakibat terjadinya rugi-rugi (pathloss) sinyal yang terjadi disepanjang saluran transmisi, yang akan mempengaruhi kualitas sinyal yang akan diterima. Sehingga perlu dilakukan perhitungan rugi-rugi (pathloss) untuk jaringan teknologi 4G LTE di kota Balikpapan untuk mengetahui peningkatan pathloss dengan penambahan jarak antara E node B- MS. Dalam menentukan rugi-rugi sinyal digunakan model propagasi COST 231 karena sesuai dengan frekuensi 4G LTE yaitu $1800 \mathrm{MHz}$ dan untuk wilayah urban Dalam penelitian ini dihitung rugi-rugi (pathloss) sinyal 4G LTE dengan variasi jarak antenna pemancar (E node B) terhadap penerima (mobile station) yaitu $1 \mathrm{~km}, 5 \mathrm{~km}, 10 \mathrm{~km}, 15 \mathrm{~km}, 20 \mathrm{~km}$, dengan ketinggian antenna pemancar 24 meter. Dari hasil perhitungan didapatkan semakin jauh jarak antara antena pemancar terhadap penerima maka nilai pathloss semakin besar yaitu dari $138.8853 \mathrm{~dB}$ menjadi $175.4915 \mathrm{~dB}$. Sedangkan jika tinggi antena penerima diperbesar dengan jarak d antara eNodeB dengan MS tetap maka nilai pathloss menjadi menurun.
\end{abstract}

Kata Kunci : 4G LTE, pathloss, model propagasi COST 231

\begin{abstract}
Abstrak-The farther the distance between sender and receiver in the mobile communication will be resulted in the losses (pathloss) signals that occur along the transmission line, which will affect the quality of the signal to be received. So that needs to be calculated losses (pathloss) for 4G LTE technology network in the city of Aberdeen to determine the pathloss increase with the addition of the distance between nodes E B- MS. In determining the loss signal used propagation model COST 231 because according to the frequency of 4G LTE $1800 \mathrm{MHz}$ and for an urban area in this study was calculated losses (pathloss) signal 4G LTE with distance variation antenna transmitter (E node B) of the recipient ( mobile station) is $1 \mathrm{~km}, 5$ $\mathrm{km}, 10 \mathrm{~km}, 15 \mathrm{~km}, 20 \mathrm{~km}$, with a transmitter antenna height of 24 meters. From the results of the calculation, the greater the distance between the transmitter antenna towards the receiver pathloss value is the greater of $138.8853175 .4915 \mathrm{~dB}$ to $\mathrm{dB}$. Meanwhile, if the receiver antenna height is enlarged to the distance $\mathrm{d}$ between the eNodeB with MS remain the pathloss value to decrease.
\end{abstract}

Keywords: 4G LTE, pathloss, model propagasi COST 231

\section{PENDAHULUAN}

Perkembangan pesat teknologi komunikasi seluler dimulai dari generasi pertama (1G) sampai pada sekarang ini generasi keempat $(4 \mathrm{G})$ didasarkan kepada kebutuhan masyarakat akan informasi dan komunikasi yang menuntut tersedianya sistem komunikasi seluler yang bermutu tinggi. Dimana akan menjadi trend perubahan kebutuhan konsumen dari komunikasi suara menjadi komunikasi data dengan kecepatan transfer yang semakin tinggi.

Teknologi 4G LTE (Long Term Evolution) dikembangkan dari suatu Third Generation
Copyright $\odot 2016$ JNTE. All rights reserved

Patnership Project (3GPP) yang merupakan pengembangan dari teknologi sebelumnya $3 \mathrm{G}$ (UMTS) yang memiliki kecepatan transfer rate 2 Mbps, dan 3,5 G (HSPA) yang mencapai 14 Mbps. LTE ini dirancang untuk memiliki kemampuan kecepatan transfer rate mencapai 100 Mbps pada sisi downlink dan 50 Mbps pada sisi uplink.

Dalam perencanaan jaringan telekomunikasi seluler termasuk 4G LTE, pada daerah urban, sub urban ataupun rural berbeda karena sinyal akan mengalami pantulan (reflected) yang berbeda disebabkan tingkat kepadatan rumah atau gedung yang berbeda. Banyaknya pantulan 
disepanjang saluran yang dilalui oleh sinyal akan menimbulkan redaman atau daya yang hilang disepanjang saluran atau yang lebih dikenal dengan istilah pathloss yang mempengaruhi kualitas sinyal. Oleh sebab itu perhitungan pathloss sangat penting dilakukan dalam perencanaan sebuah jaringan telekomunikasi.

\section{TINJAUAN PUSTAKA}

\subsection{Teknologi 4G LTE}

LTE (Long Term Evolution) dikembangkan oleh Third Generation Patnership Project (3GPP) untuk memperbaiki teknologi sebelumnya yaitu 3G dan 3,5 G. Spesifikasi LTE ditargetkan untuk melayani downlink sedikitnya 100 Mbps dan uplink 50 Mbps [3]. Gambar 1 merupakan konfigurasi jaringan LTE.

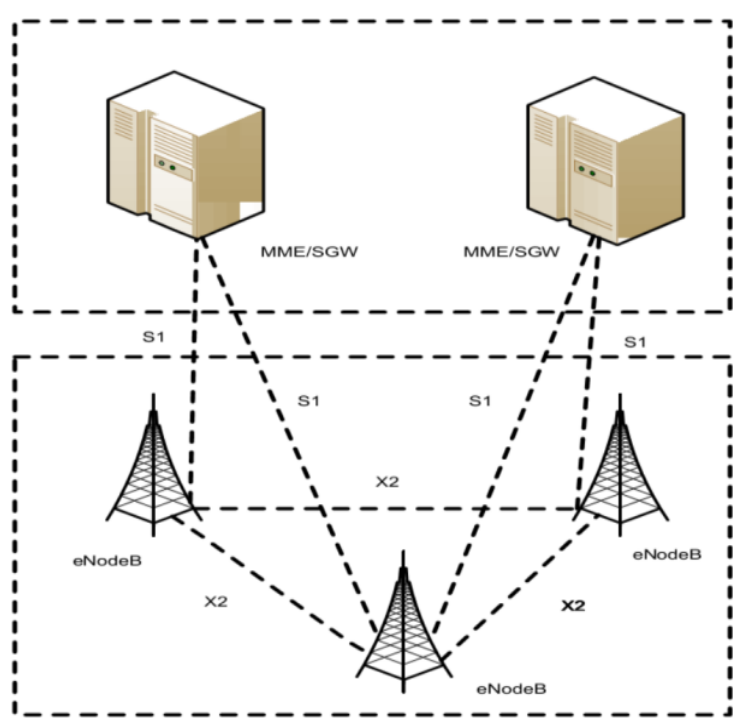

Gambar 1. Arsitektur Jaringan LTE

\subsection{Perambatan Gelombang Radio}

Propagasi adalah suatu metode proses perambatan gelombang radio dari pemancar $(T x)$ ke penerima $(R x)$ dan media transmisi sinyal yang digunakan adalah dengan media non-kawat (unguided) serta, memerlukan antenna untuk meradiasikan sinyalnya ke udara bebas dan bentuk sinyal yang dipancarkan oleh pemancar adalah berupa gelombang sinyal elektromagnetik. Gelombang elektromagnetik ini akan merambat melalui udara bebas menuju antenna penerima dan sinyal yang ditransmisikan oleh pemancar tersebut akan mengalami peredaman sepanjang lintasan yang dilaluinya, sehingga ketika sampai di antenna penerima, energi sinyal sudah sangat lemah.

Mekanisme propagasi gelombang dalam sistem wireless memiliki 3 jenis yaitu [6]:

1. Reflection adalah pantulan atau yang dikenal dengan (refleks) yang berlangsung ketika gelombang elektromagnetik mengenai objek yang memiliki dimensi jauh lebih besar dari panjang gelombang yang dipancarkan. Dan pantulan dapat terjadi pada permukaan tanah gedung serta tembok contoh: Permukaan bumi, bangunan dan dinding.

2. Diffraction adalah penguraian sinyal (difraksi yang) berlangsung ketika radio $T x$ dan $R x$ bertabrakan atau dibelokan oleh benda yang memiliki sisi ujung lintasan yang tajam (sharp edge). Gelombang- gelombang yang dihasilkan dari difraksi ini juga akan mmepengaruhi gelombang yang akan diterima meskipun bentuk halangan tidak terlihat secara langsung. Pada frekuensi tinggi difraksi sangat bergantung dengan bentuk objek.

3. Scattering adalah hamburan sinyal yang terjadi ketika saat sinyal mengenai objek yang mempunyai dimensi lebih kecil dibandingkan panjang gelombang sinyal sehingga menyebabkan energi menyebar kesegala arah. Hamburan dihasilkan oleh permukaan yang kasar, benda kecil, atau dapat disebabkan oleh ketidak teraturan dalam saluran frekuensi.

\subsection{PathLoss}

Path Loss adalah (melemah/hilangnya) kekuatan daya sinyal informasi yang dipancarkan oleh antenna pengirim sinyal $(T x)$ menuju penerima $(R x)$ yang berlangsung selama data/sinyal melewati media udara dan terjadi selama proses transmisi sinyal berlangsung dari antenna pengirim menuju penerima dalam jarak tertentu. Faktor-faktor yang mempengaruhi nilai level daya dan pathloss adalah jarak pengukuran antara $(T x)$ dan $(R x)$, tinggi antena (Tx dan $R x$ ), serta jenis area pengukuran yang digunakan.

Model Propagasi COST 231:

Model propagasi jenis ini untuk mengestimasi pathloss di daerah urban dan beroperasi pada range frekuensi $1500 \mathrm{MHz}$ $2000 \mathrm{MHz}$.[10]

Karakteristik model propagasi Cost 231: 
1. Range frekuensi :1500-2000 MHz

2. $\mathrm{B}_{\mathrm{S}}\left(\mathrm{h}_{\mathrm{te}}\right): 30-200 \mathrm{~m}$ (Tinggi efektif antenna transmiter)

3. $\mathrm{M}_{\mathrm{S}}\left(\mathrm{h}_{\mathrm{re}}\right): 1-10 \mathrm{~m}$ (Tinggi efektif antenna receiver)

4. d : 1-20 Km (Jarak Bs - Ms)

a $\left(\mathrm{h}_{\mathrm{re}}\right)$ : adalah faktor koreksi untuk tinggi antenna MS yang tergantung ukuran coverage area

Untuk daerah kecil :

$a\left(h_{r e}\right)=\left(1,1 \log F_{c}-0,7\right) h_{r e}-\left(1,56 \log f_{c}-0,8\right)$

Untuk daerah luas :

$\mathrm{a}\left(\mathrm{h}_{\mathrm{re}}\right)=\left(8,29\left(\log 1,54 \mathrm{~h}_{\mathrm{re}}\right)^{2}-1,1\right), \mathrm{f}_{\mathrm{c}} \geq 300 \mathrm{Mhz}$

$a\left(h_{r e}\right)=\left(3,2\left(\log 11,75 h_{r e}\right)^{2}-4,97\right), f_{c} \leq 300 \mathrm{Mhz}$

Untuk model propagasi jenis cost 231 dapat menggunakan persamaan :

$L($ urban $)=46,3+33,9 \log f_{c}-13,82 \log h_{t e}-$ $a\left(h_{r e}\right)+\left(44,9-6,55 \log h_{t e}\right) \log d+C M$

Nilai $\mathrm{CM} \quad \longrightarrow \quad$ untuk daerah small dan medium city $=0 \mathrm{~dB}$

Nilai $\mathrm{CM} \longrightarrow$ untuk daerah large city (metropolitan center) $=3 \mathrm{~dB}$

\subsection{Klasifikasi Daerah}

Berdasarkan keberadaan penghalang dan tingkat kepadatan (obstacle) suatu halangan yang dapat menggangu proses pentransmisian yang berlangsung maka daerah dibagi menjadi tiga yaitu [7]:

1. Daerah Urban

Adalah daerah wilayah yang dipadati penduduk dengan bangunan-bangunan besar dan memiliki gedung-gedung yang rapat serta tinggi

2. Daerah Sub Urban

Kategori daerah yang memiliki jumlah bangunan yang mulai padat dan tinggi ratarata bangunan antara $12-20 \mathrm{~m}$ dan lebar 18 $30 \mathrm{~m}$

3. Daerah Rural

Adalah kategori jenis wilayah yang memiliki jumlah bangunan sedikit dan jarang atau dapat berupa alam terbuka.

\section{METODOLOGI}

\subsection{Tahapan Penelitian}

Untuk tahapan penelitian antara lain:

1. Menentukan frekuensi LTE yang akan diteliti

2. Menentukan area eNode B

3. Menghitung nilai a(hre) untuk masingmasing daerah layanan

4. Menghitung pathloss untuk masing-masing daerah layanan

\subsection{Diagram alir penelitian}

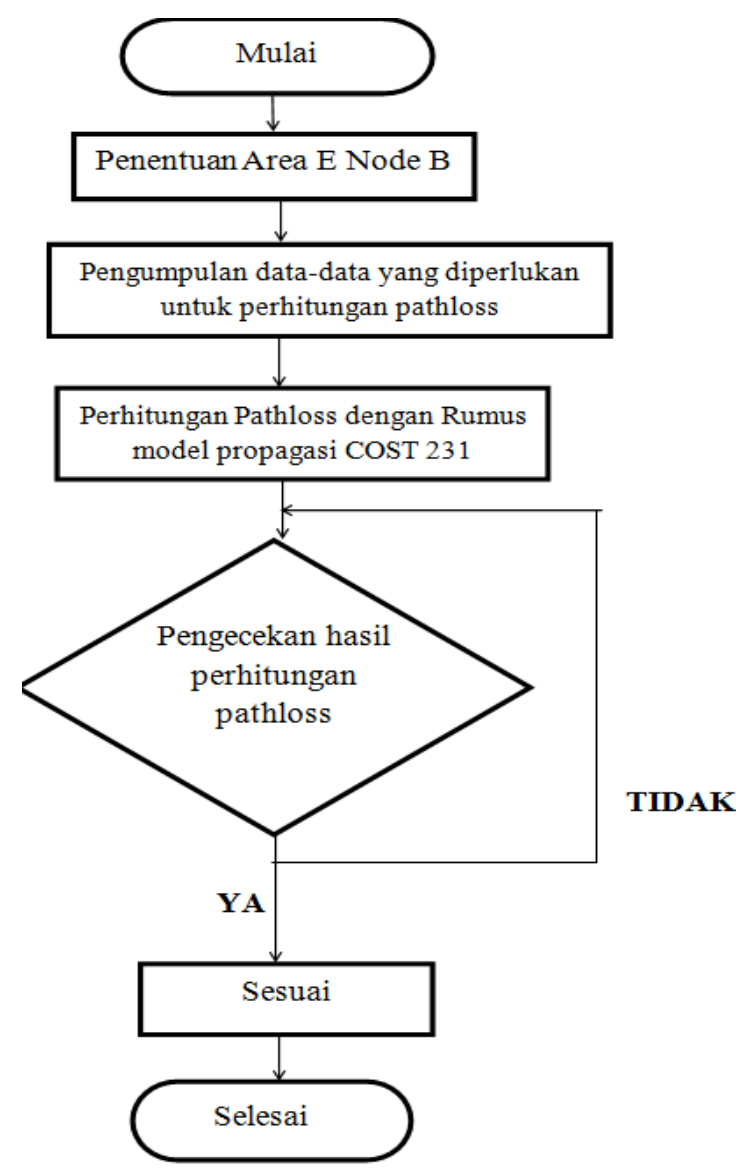

Gambar 2. Diagram alir penelitian

Penjelasan digram alir:

1. Penentuan area $E$ node $B$

Dalam penelitian ini di ambil sample E node

B untuk area urban, karena teknologi $4 \mathrm{G}$ LTE di kota Balikpapan masih dalam perluasan ke area sub urban dan rural

2. Pengumpulan data-data yang diperlukan untuk perhitungan antara lain:

a. Frekuensi 4G LTE yang digunakan di Balikpapan

b. Tinggi antenna E node B 
c. Jarak antara E node B terhadap mobile station (MS)

d. dsb

3. Perhitungan pathloss teknologi 4G LTE dengan model propagasi COST 231

a. Digunakannya model propagasi COST 231 sesuai dengan range frekuensi 4G LTE yang ada di Balikpapan yaitu 1800 $\mathrm{MHz}$

b. Menghitung pathloss dengan pembagian jarak E node B- MS yaitu 1, 5, 10, 15, 20 $\mathrm{km}$.

4. Pengecekan hasil perhitungan pathloss yang telah dilakukan.

Dalam hal ini dilakukan pengecekan kembali terhadap perhitungan yang telah dilakukan untuk menghindari kesalahan dalam perhitungan karena ada banyak parameter yang dimasukkan.

5. Jika dalam perhitungan pathloss tidak ada kekeliruan maka proses ini dapat diselesaikan

Pada pembahasan ini data yang digunakan adalah data yang telah diperoleh dari PT. Indosat Ooredoo yaitu teknologi 4G, frekuensi 1800 $\mathrm{MHz}$ pada sampel kategori wilayah kota Balikpapan antara lain:

e Node B Lokasi daerah Jenderal Sudirman, Bs $\left(\mathrm{h}_{\mathrm{te}}\right)=24 \mathrm{~m}$

Dalam melakukan perhitungan pathloss pada penelitian ini penulis menggunakan beberapa variasi dari tinggi antenna penerima $\mathrm{M}_{\mathrm{S}}\left(\mathrm{h}_{\mathrm{re}}\right)$ dan jarak d (Jarak Bs - Ms)

Tabel 1. Tabel variasi parameter perhitungan Pathloss

\begin{tabular}{|c|c|c|}
\hline No & $\begin{array}{c}\text { Tinggi antenna MS, } \mathrm{h}_{\mathrm{re}} \\
(\text { meter })\end{array}$ & Jarak, $\mathrm{d}(\mathrm{km})$ \\
\hline 1 & 1 & $1,5,10,15,20$ \\
\hline 2 & 2 & $1,5,10,15,20$ \\
\hline 3 & 3 & $1,5,10,15,20$ \\
\hline 4 & 4 & $1,5,10,15,20$ \\
\hline 5 & 5 & $1,5,10,15,20$ \\
\hline 6 & 6 & $1,5,10,15,20$ \\
\hline 7 & 7 & $1,5,10,15,20$ \\
\hline 8 & 8 & $1,5,10,15,20$ \\
\hline 9 & 9 & $1,5,10,15,20$ \\
\hline 10 & 10 & $1,5,10,15,20$ \\
\hline
\end{tabular}

\section{HASIL DAN PEMBAHASAN}

\subsection{Perhitungan Pathloss 4G LTE}

4.1.1. Perhitungan Pathloss 4G LTE untuk MS $\left(h_{r e}\right) 1$ meter

Untuk melakukan perhitungan Pathloss

4G LTE untuk MS $\left(\left(\mathrm{h}_{\mathrm{re}}\right) 1\right.$ meter

Frekuensi $=1800 \mathrm{MHz}$ (Frekuensi 4G LTE)

Bs $\left(h_{t e}\right)=24 \mathrm{~m}$ (Tinggi antena e node $\left.\mathrm{B}\right)$

$\operatorname{Ms}\left(h_{r e}\right)=1($ Tinggi antenna MS )

$\mathrm{d} \quad=1 \mathrm{~km} \quad$ (Jarak Bs- Ms)

Untuk penelitian ini diambil nilai a $\left(\mathrm{h}_{\mathrm{re}}\right)$ untuk daerah luas

Nilai $\mathrm{CM}=0 \mathrm{~dB}$, daerah small dan medium city

$$
\begin{aligned}
\mathrm{a}\left(\mathrm{h}_{\mathrm{re}}\right)= & \left(3,2\left(\log 11,75 \mathrm{~h}_{\mathrm{re}}\right)^{2}-4,97\right) \\
& \quad \text { untuk } \mathrm{f}_{\mathrm{c}} \geq 300 \mathrm{Mhz} \\
= & \left(3,2(\log 11,75.1)^{2}-4,97\right) \\
= & -1.306060685
\end{aligned}
$$

Untuk model propagasi Cost 231 maka pengukuran pathloss dilakukan untuk area urban dapat menggunakan persamaan :

$$
\begin{aligned}
\mathrm{L}(\text { urban })= & 46,3+33,9 \log \mathrm{f}_{\mathrm{c}}-13,82 \log \mathrm{h}_{\mathrm{te}}- \\
& \mathrm{a}\left(\mathrm{h}_{\mathrm{re}}\right)+\left(44,9-6,55 \operatorname{logh} \mathrm{t}_{\mathrm{te}}\right) \log \mathrm{d}+ \\
& \mathrm{CM} \\
= & 46,3+33.9 \log 1800-13.82 \log 24 \\
& -(-1.306060685)+(44,9-6,55 \log \\
& 24) \log 1+0 \\
= & 138.8853 \mathrm{~dB}
\end{aligned}
$$

Untuk perhitungan pathloss 4G LTE MS $\left(\left(\mathrm{h}_{\mathrm{re}}\right) 1\right.$ meter dengan variasi $\mathrm{d}=1 \mathrm{~km}, 5 \mathrm{~km}, 10$ $\mathrm{km}, 15 \mathrm{~km}, 20 \mathrm{~km}$ diberikan pada Tabel 2 :

Tabel 2. Perhitungan Pathloss 4G LTE MS $\left(\mathrm{h}_{\mathrm{re}}\right)$ 1 meter

\begin{tabular}{|c|c|c|c|}
\hline No & $\begin{array}{c}\text { Tinggi antenna } \\
\text { MS, }\end{array}$, (meter) & Jarak, d (km) & Pathloss (dB) \\
\hline 1 & 1 & 1 & 138.8853 \\
\hline 2 & 1 & 5 & 163.9501 \\
\hline 3 & 1 & 10 & 174.7449 \\
\hline 4 & 1 & 15 & 181.0595 \\
\hline 5 & 1 & 20 & 185.5397 \\
\hline
\end{tabular}

\subsubsection{Perhitungan Pathloss 4G LTE untuk MS $\left(h_{r e}\right) 2$ meter}

Untuk perhitungan pathloss 4G LTE MS $\left(\mathrm{h}_{\mathrm{re}}\right) 2$ meter dengan variasi $\mathrm{d}=1 \mathrm{~km}, 5 \mathrm{~km}, 10$ $\mathrm{km}, 15 \mathrm{~km}, 20 \mathrm{~km}$ diberikan pada Tabel 3 : 
Tabel 3. Perhitungan Pathloss 4G LTE MS $\left(\mathrm{h}_{\mathrm{re}}\right)$ 2 meter

\begin{tabular}{|c|c|c|c|}
\hline No & $\begin{array}{c}\text { Tinggi antenna } \\
\text { MS, } \mathrm{h}_{\text {re }}(\text { meter })\end{array}$ & $\begin{array}{c}\text { Jarak, d } \\
(\mathrm{km})\end{array}$ & $\begin{array}{c}\text { Pathloss } \\
(\mathrm{dB})\end{array}$ \\
\hline 1 & 2 & 1 & 136.5338 \\
\hline 2 & 2 & 5 & 161.5986 \\
\hline 3 & 2 & 10 & 172.3934 \\
\hline 4 & 2 & 15 & 178.708 \\
\hline 5 & 2 & 20 & 183.1882 \\
\hline
\end{tabular}

\subsubsection{Perhitungan Pathloss 4G LTE untuk MS ( $\left.h_{r e}\right) 3$ meter}

Untuk perhitungan pathloss 4G LTE MS $\left(\left(\mathrm{h}_{\mathrm{re}}\right) 3\right.$ meter dengan variasi $\mathrm{d}=1 \mathrm{~km}, 5 \mathrm{~km}, 10$ $\mathrm{km}, 15 \mathrm{~km}, 20 \mathrm{~km}$ diberikan pada Tabel 4 :

Tabel 4. Perhitungan Pathloss 4G LTE MS ( $\left(\mathrm{h}_{\mathrm{re}}\right)$ 3 meter

\begin{tabular}{|c|c|c|c|}
\hline No & $\begin{array}{c}\text { Tinggi antenna } \\
\text { MS, } \mathrm{h}_{\mathrm{re}}(\text { meter })\end{array}$ & $\begin{array}{c}\text { Jarak, } \\
\mathrm{d}(\mathrm{km})\end{array}$ & $\begin{array}{c}\text { Pathloss } \\
(\mathrm{dB})\end{array}$ \\
\hline 1 & 3 & 1 & 134.8894 \\
\hline 2 & 3 & 5 & 159.9542 \\
\hline 3 & 3 & 10 & 170.749 \\
\hline 4 & 3 & 15 & 177.0636 \\
\hline 5 & 3 & 20 & 181.5438 \\
\hline
\end{tabular}

\subsubsection{Perhitungan Pathloss 4G LTE untuk} MS $\left(h_{\text {re }}\right) 4$ meter

Untuk perhitungan pathloss 4G LTE MS $\left(\left(\mathrm{h}_{\mathrm{re}}\right) 4\right.$ meter dengan variasi $\mathrm{d}=1 \mathrm{~km}, 5 \mathrm{~km}, 10$ $\mathrm{km}, 15 \mathrm{~km}, 20 \mathrm{~km}$ diberikan pada Tabel 5 :

Tabel 5. Perhitungan Pathloss 4G LTE MS ((h $\left.\mathrm{h}_{\text {re }}\right)$ 4 meter

\begin{tabular}{|c|c|c|c|}
\hline No. & $\begin{array}{c}\text { Tinggi antenna } \\
\text { MS, } \mathrm{h}_{\mathrm{re}}(\mathrm{meter})\end{array}$ & $\begin{array}{c}\text { Jarak, } \\
\mathrm{d}(\mathrm{km})\end{array}$ & $\begin{array}{c}\text { Pathloss } \\
(\mathrm{dB})\end{array}$ \\
\hline 1 & 4 & 1 & 133.6023 \\
\hline 2 & 4 & 5 & 158.6671 \\
\hline 3 & 4 & 10 & 169.4619 \\
\hline 4 & 4 & 15 & 175.7765 \\
\hline 5 & 4 & 20 & 180.2567 \\
\hline
\end{tabular}

\subsubsection{Perhitungan Pathloss 4G LTE untuk MS $\left(h_{\text {re }}\right) 5$ meter}

Untuk perhitungan pathloss 4G LTE MS $\left(\left(\mathrm{h}_{\mathrm{re}}\right) 5\right.$ meter dengan variasi $\mathrm{d}=1 \mathrm{~km}, 5 \mathrm{~km}, 10$ $\mathrm{km}, 15 \mathrm{~km}, 20 \mathrm{~km}$ diberikan pada Tabel 6:
Tabel 6. Perhitungan Pathloss 4G LTE MS ((h $\left.\mathrm{h}_{\mathrm{re}}\right)$ 5 meter

\begin{tabular}{|c|c|c|c|}
\hline No. & $\begin{array}{c}\text { Tinggi antenna } \\
\text { MS, } \mathrm{h}_{\mathrm{re}}(\text { meter })\end{array}$ & $\begin{array}{c}\text { Jarak, d } \\
(\mathrm{km})\end{array}$ & $\begin{array}{c}\text { Pathloss } \\
(\mathrm{dB})\end{array}$ \\
\hline 1 & 5 & 1 & 132.5352 \\
\hline 2 & 5 & 5 & 157.6 \\
\hline 3 & 5 & 10 & 168.3948 \\
\hline 4 & 5 & 15 & 174.7094 \\
\hline 5 & 5 & 20 & 179.1896 \\
\hline
\end{tabular}

\subsubsection{Perhitungan Pathloss 4G LTE untuk} MS ( $\left.h_{\text {re }}\right) 6$ meter

Untuk perhitungan pathloss 4G LTE MS $\left(\mathrm{h}_{\text {re }}\right) 6$ meter dengan variasi $\mathrm{d}=1 \mathrm{~km}, 5 \mathrm{~km}, 10$ km, 15 km, 20 km diberikan pada Tabel 7 :

Tabel 7. Perhitungan Pathloss 4G LTE MS $\left(\left(\mathrm{h}_{\mathrm{re}}\right)\right.$ 6 meter

\begin{tabular}{|c|c|c|c|}
\hline No & $\begin{array}{c}\text { Tinggi antenna } \\
\text { MS, } \mathrm{h}_{\mathrm{re}}(\text { meter })\end{array}$ & $\begin{array}{c}\text { Jarak, d } \\
(\mathrm{km})\end{array}$ & Pathloss $(\mathrm{dB})$ \\
\hline 1 & 6 & 1 & 131.6186 \\
\hline 2 & 6 & 5 & 156.6834 \\
\hline 3 & 6 & 10 & 167.4783 \\
\hline 4 & 6 & 15 & 173.7928 \\
\hline 5 & 6 & 20 & 178.2731 \\
\hline
\end{tabular}

\subsubsection{Perhitungan Pathloss 4G LTE untuk} MS $\left(h_{r e}\right) 7$ meter

Untuk perhitungan pathloss 4G LTE MS $\left(\left(\mathrm{h}_{\mathrm{re}}\right) 7\right.$ meter dengan variasi $\mathrm{d}=1 \mathrm{~km}, 5 \mathrm{~km}, 10$ $\mathrm{km}, 15 \mathrm{~km}, 20 \mathrm{~km}$ diberikan pada Tabel 8 :

Tabel 8. Perhitungan Pathloss 4G LTE MS (( $\left.\mathrm{h}_{\mathrm{re}}\right)$ 7 meter

\begin{tabular}{|c|c|c|c|}
\hline No. & $\begin{array}{c}\text { Tinggi antenna } \\
\text { MS, } \mathrm{h}_{\text {re }} \text { (meter) }\end{array}$ & $\begin{array}{c}\text { Jarak, } \\
\mathrm{d}(\mathrm{km})\end{array}$ & $\begin{array}{c}\text { Pathloss } \\
(\mathrm{dB})\end{array}$ \\
\hline 1 & 7 & 1 & 130.8124 \\
\hline 2 & 7 & 5 & 155.8772 \\
\hline 3 & 7 & 10 & 166.672 \\
\hline 4 & 7 & 15 & 172.9866 \\
\hline 5 & 7 & 20 & 177.4669 \\
\hline
\end{tabular}

\subsubsection{Perhitungan Pathloss 4G LTE untuk} MS $\left(h_{r e}\right) 8$ meter

Untuk perhitungan pathloss 4G LTE MS $\left(\left(\mathrm{h}_{\mathrm{re}}\right) 8\right.$ meter dengan variasi $\mathrm{d}=1 \mathrm{~km}, 5$ $\mathrm{km}, 10 \mathrm{~km}, 15 \mathrm{~km}, 20 \mathrm{~km}$ diberikan pada Tabel 9 : 
Tabel 9. Perhitungan Pathloss 4G LTE MS ((h $\left.\mathrm{h}_{\mathrm{re}}\right)$ 8 meter

\begin{tabular}{|c|c|c|c|}
\hline NO & $\begin{array}{c}\text { Tinggi antenna } \\
\text { MS, } \mathrm{h}_{\text {re }}(\text { meter })\end{array}$ & $\begin{array}{c}\text { Jarak, d } \\
(\mathrm{km})\end{array}$ & $\begin{array}{c}\text { Pathloss } \\
(\mathrm{dB})\end{array}$ \\
\hline 1 & 8 & 1 & 130.0909 \\
\hline 2 & 8 & 5 & 155.1557 \\
\hline 3 & 8 & 10 & 165.9505 \\
\hline 4 & 8 & 15 & 172.2651 \\
\hline 5 & 8 & 20 & 176.7453 \\
\hline
\end{tabular}

\subsubsection{Perhitungan Pathloss 4G LTE untuk} MS ( $\left.h_{r e}\right) 9$ meter

Untuk perhitungan pathloss 4G LTE MS $\left(\left(\mathrm{h}_{\mathrm{re}}\right) 9\right.$ meter dengan variasi $\mathrm{d}=1 \mathrm{~km}, 5 \mathrm{~km}, 10$ $\mathrm{km}, 15 \mathrm{~km}, 20 \mathrm{~km}$ diberikan pada Tabel 10 :

Tabel 10. Perhitungan Pathloss 4G LTE MS $\left(\left(\mathrm{h}_{\mathrm{re}}\right) 9\right.$ meter

\begin{tabular}{|c|c|c|c|}
\hline No. & $\begin{array}{c}\text { Tinggi antenna } \\
\text { MS, } \mathrm{h}_{\mathrm{re}}(\text { meter })\end{array}$ & $\begin{array}{c}\text { Jarak, d } \\
(\mathrm{km})\end{array}$ & $\begin{array}{c}\text { Pathloss } \\
(\mathrm{dB})\end{array}$ \\
\hline 1 & 9 & 1 & 129.4365 \\
\hline 2 & 9 & 5 & 154.5013 \\
\hline 3 & 9 & 10 & 165.2962 \\
\hline 4 & 9 & 15 & 171.6107 \\
\hline 5 & 9 & 20 & 176.091 \\
\hline
\end{tabular}

4.1.10. Perhitungan Pathloss 4G LTE untuk MS $\left(h_{\mathrm{re}}\right) \mathbf{1 0}$ meter

Untuk perhitungan pathloss 4G LTE MS $\left(\left(\mathrm{h}_{\mathrm{re}}\right) 10\right.$ meter dengan variasi $\mathrm{d}=1 \mathrm{~km}, 5 \mathrm{~km}, 10$ $\mathrm{km}, 15 \mathrm{~km}, 20 \mathrm{~km}$ diberikan pada Tabel 11:

Tabel 11. Perhitungan Pathloss 4G LTE MS $\left(\left(\mathrm{h}_{\mathrm{re}}\right) 10\right.$ meter

\begin{tabular}{|c|c|c|c|}
\hline No. & $\begin{array}{c}\text { Tinggi antenna } \\
\text { MS, } \mathrm{h}_{\mathrm{re}}(\text { meter })\end{array}$ & $\begin{array}{c}\text { Jarak, d } \\
(\mathrm{km})\end{array}$ & $\begin{array}{c}\text { Pathloss } \\
(\mathrm{dB})\end{array}$ \\
\hline 1 & 10 & 1 & 128.8337 \\
\hline 2 & 10 & 5 & 153.9018 \\
\hline 3 & 10 & 10 & 164.6967 \\
\hline 4 & 10 & 15 & 171.0112 \\
\hline 5 & 10 & 20 & 175.4915 \\
\hline
\end{tabular}

4.2. Perbandingan Pathloss dengan Nilai MS $\left(h_{\text {re }}\right)$ yang Semakin Besar

1. Untuk nilai $\mathrm{d}=1 \mathrm{~km}, \mathrm{BS}$ hte $=24 \mathrm{~m}$, nilai $\mathrm{MS}$ hre dari $1 \mathrm{~m}-10 \mathrm{~m}$
Tabel 12. Perbandingan Pathloss $\mathrm{d}=1 \mathrm{~km}, \mathrm{BS}$ hte $=24 \mathrm{~m}$, MS hre $1-10 \mathrm{~m}$

\begin{tabular}{|c|c|c|}
\hline \multirow{4}{*}{$\begin{array}{c}\text { d = 1km, } \\
\text { BS hte = 24 m, } \\
(\text { meter })\end{array}$} & $\begin{array}{c}\text { Pathloss } \\
(\mathrm{dB})\end{array}$ \\
\cline { 2 - 3 } & 1 & 138.8853 \\
\cline { 2 - 3 } & 2 & 136.5338 \\
\cline { 2 - 3 } & 3 & 134.8894 \\
\cline { 2 - 3 } & 4 & 133.6023 \\
\cline { 2 - 3 } & 5 & 132.5352 \\
\cline { 2 - 3 } & 6 & 131.6186 \\
\cline { 2 - 3 } & 7 & 130.8124 \\
\cline { 2 - 3 } & 8 & 130.0909 \\
\cline { 2 - 3 } & 9 & 129.4365 \\
\hline
\end{tabular}

2. Untuk nilai $\mathrm{d}=5 \mathrm{~km}, \mathrm{BS}$ hte $=24 \mathrm{~m}$, nilai MS hre dari $1 \mathrm{~m}-10 \mathrm{~m}$

Tabel 13. Perbandingan Pathloss $\mathrm{d}=5 \mathrm{~km}$, BS hte $=24 \mathrm{~m}$, MS hre $1-10 \mathrm{~m}$

\begin{tabular}{|c|c|c|}
\hline \multirow{4}{*}{$\begin{array}{c}\mathrm{d}=5 \mathrm{~km}, \\
\text { BS hte = 24 m, } \\
(\text { meter })\end{array}$} & $\begin{array}{c}\text { Pathloss } \\
(\mathrm{dB})\end{array}$ \\
\cline { 2 - 3 } & 1 & 163.9501 \\
\cline { 2 - 3 } & 2 & 161.5986 \\
\cline { 2 - 3 } & 3 & 159.9542 \\
\cline { 2 - 3 } & 4 & 158.6671 \\
\cline { 2 - 3 } & 5 & 157.6 \\
\cline { 2 - 3 } & 6 & 156.6834 \\
\cline { 2 - 3 } & 7 & 155.8772 \\
\cline { 2 - 3 } & 8 & 155.1557 \\
\cline { 2 - 3 } & 9 & 154.5013 \\
\hline & 10 & 153.9018 \\
\hline
\end{tabular}

3. Untuk nilai $\mathrm{d}=10 \mathrm{~km}$, BS hte $=24 \mathrm{~m}$, nilai MS hre dari $1 \mathrm{~m}-10 \mathrm{~m}$

Tabel 14. Perbandingan Pathloss $\mathrm{d}=10 \mathrm{~km}, \mathrm{BS}$ hte $=24 \mathrm{~m}$, MS hre $1-10 \mathrm{~m}$

\begin{tabular}{|c|c|c|}
\hline \multirow{4}{*}{$\begin{array}{c}\text { d = 10 km, } \\
\text { BS hte = 24 m, }\end{array}$} & $\begin{array}{c}\text { MS, } \mathrm{h}_{\mathrm{re}} \\
(\mathrm{meter})\end{array}$ & $\begin{array}{c}\text { Pathloss } \\
(\mathrm{dB})\end{array}$ \\
\cline { 2 - 3 } & 1 & 174.7449 \\
\cline { 2 - 3 } & 2 & 172.3934 \\
\cline { 2 - 3 } & 3 & 170.749 \\
\cline { 2 - 3 } & 4 & 169.4619 \\
\cline { 2 - 3 } & 5 & 168.3948 \\
\cline { 2 - 3 } & 6 & 167.4783 \\
\cline { 2 - 3 } & 7 & 166.672 \\
\cline { 2 - 3 } & 8 & 165.9505 \\
\cline { 2 - 3 } & 9 & 165.2962 \\
\cline { 2 - 3 } & 10 & 164.6967 \\
\hline
\end{tabular}


4. Untuk nilai $\mathrm{d}=15 \mathrm{~km}, \mathrm{BS}$ hte $=24 \mathrm{~m}$, nilai MS hre dari $1 \mathrm{~m}-10 \mathrm{~m}$

Tabel 15. Perbandingan Pathloss $\mathrm{d}=15 \mathrm{~km}$, BS hte $=24 \mathrm{~m}$, MS hre 1-10 m

\begin{tabular}{|c|c|c|}
\hline \multirow{4}{*}{\begin{tabular}{c} 
d = \\
BS hte $=24 \mathrm{~km}$, \\
\cline { 2 - 3 }
\end{tabular}} & $\begin{array}{c}\text { MS, } \mathrm{h}_{\mathrm{re}} \\
(\mathrm{meter})\end{array}$ & $\begin{array}{c}\text { Pathloss } \\
(\mathrm{dB})\end{array}$ \\
\cline { 2 - 3 } & 2 & 181.0595 \\
\cline { 2 - 3 } & 3 & 178.708 \\
\cline { 2 - 3 } & 4 & 177.0636 \\
\cline { 2 - 3 } & 5 & 174.7094 \\
\cline { 2 - 3 } & 6 & 173.7928 \\
\cline { 2 - 3 } & 8 & 172.9866 \\
\cline { 2 - 3 } & 9 & 172.2651 \\
\cline { 2 - 3 } & 10 & 171.0112 \\
\hline
\end{tabular}

5. Untuk nilai $\mathrm{d}=20 \mathrm{~km}$, $\mathrm{BS}$ hte $=24 \mathrm{~m}$, nilai MS hre dari $1 \mathrm{~m}-10 \mathrm{~m}$

Tabel 16. Perbandingan Pathloss $\mathrm{d}=20 \mathrm{~km}$, BS the $=24 \mathrm{~m}$, MS hre $1-10 \mathrm{~m}$

\begin{tabular}{|c|c|c|}
\hline \multirow{4}{*}{$\begin{array}{c}\mathrm{d}=20 \mathrm{~km}, \\
\text { BS hte = }\end{array}$} & $\begin{array}{c}\text { MS }, \mathrm{h}_{\mathrm{re}} \\
(\text { meter })\end{array}$ & $\begin{array}{c}\text { Pathloss } \\
(\mathrm{dB})\end{array}$ \\
\cline { 2 - 3 } & 1 & 185.5397 \\
\cline { 2 - 3 } & 2 & 183.1882 \\
\cline { 2 - 3 } & 3 & 181.5438 \\
\cline { 2 - 3 } & 4 & 180.2567 \\
\cline { 2 - 3 } & 5 & 179.1896 \\
\cline { 2 - 3 } & 6 & 178.2731 \\
\cline { 2 - 3 } & 7 & 177.4669 \\
\cline { 2 - 3 } & 8 & 176.7453 \\
\cline { 2 - 3 } & 9 & 176.091 \\
\cline { 2 - 3 } & 10 & 175.4915 \\
\hline
\end{tabular}

\section{KESIMPULAN}

Dari hasil perhitungan pathlosss dan analisa yang telah dilakukan maka didapatkan beberapa kesimpulan sebagai berikut :

1. Semakin jauh jarak antara Mobile Station (MS) terhadap e Node B maka semakin besar pathloss yang terjadi yaitu dari $138.8853 \mathrm{~dB}$ sampai $175.4915 \mathrm{~dB}$

2. Penambahan tinggi antenna di sisi penerima (MS) dengan jarak d yang tetap $(\mathrm{d}=1 \mathrm{~km})$ akan membuat nilai pathloss akan mengalami penurunan yaitu $138.8853 \mathrm{~dB}$ menjadi $128.837 \mathrm{~dB}$
3. Penambahan tinggi antenna di sisi penerima (MS) dengan jarak d yang tetap $(\mathrm{d}=5 \mathrm{~km})$ akan membuat nilai pathloss akan mengalami penurunan yaitu $163.9501 \mathrm{~dB}$ menjadi $153.9018 \mathrm{~dB}$

4. Penambahan tinggi antenna di sisi penerima (MS) dengan jarak d yang tetap $(\mathrm{d}=10 \mathrm{~km})$ akan membuat nilai pathloss akan mengalami penurunan yaitu $174.7449 \mathrm{~dB}$ menjadi $164.6967 \mathrm{~dB}$

5. Penambahan tinggi antenna di sisi penerima (MS) dengan jarak d yang tetap $(\mathrm{d}=15 \mathrm{~km})$ akan membuat nilai pathloss akan mengalami penurunan yaitu $181.0595 \mathrm{~dB}$ menjadi $171.0112 \mathrm{~dB}$

6. Penambahan tinggi antenna di sisi penerima (MS) dengan jarak d yang tetap $(\mathrm{d}=20 \mathrm{~km})$ akan membuat nilai pathloss akan mengalami penurunan yaitu $185.5397 \mathrm{~dB}$ menjadi $175.4915 \mathrm{~dB}$

\section{DAFTAR PUSTAKA}

[1] Hutahuruk, Sindak. (2011). "Simulasi Empiris Okumura Hata dan Cost 231 Pada Komunikasi Seluler". Jurnal Semantik hal 1-9.

[2] Irianto, Reza., Purnomo, Edy., Analisis Nilai Level Daya Terima Menggunakan Model Walfsich Ikegami". Univ Brawijaya

[3] Kurniawan, Uke. "Fudamental Teknologi Seluler LTE”, Rekayasa Sains, 2012

[4] Kurniawan, Uke. "Pengantar Telekomunikasi”, Informatika, 2010

[5] Nindito,S., Siswandari, N.,Puspitorini,Okkie., "Analisa Pathloss Exponent Pada Daerah Urban dan Sub Urban".PENS-ITS

[6] Rappaport, Theodore S., "Wireless Communcation Principles and Practice", Prentice Hall, 1996.

[7] Sari, Nilam.2016, "Tugas Akhir : Analisa Perhitungan Pathloss Sinyal Node B daerah Urban , Sub Urban, Rural Kota Balikpapan", Jurusan Teknik Elektronika, Politeknik Negeri Balikpapan

[8] Setiyanto, Budi."Dasar-dasar Telekomunikasi", Sakti, 2010

[9] Smale,"Sistem Telekomunikasi I", Erlangga, 1986 
[10] Wibisono, Kurniawan. “ Konsep Teknologi Seluer”, Informatika, 2008

[11] Wardhana, Lingga. "4G Handbook Edisi Bahasa Indonesia”, Nulis Buku, 2014

\section{Biodata Penulis}

Maria Ulfah, S.T., M.T, Menamatkan pendidikan S1 dari Jurusan Teknik Elektro peminatan Teknik Telekomunikasi Universitas Gadjah Mada (UGM) Yogyakarta tahun 2005, kemudian melanjutkan pendidikan Srata 2 di Institut Teknologi Telkom (d/h STTTelkom) Bandung pada jurusan Teknik Telekomunikasi. Saat ini aktif sebagai staff pengajar di jurusan Teknik Elektronika Politeknik Negeri Balikpapan 